\title{
Determining Rheumatology Patient Interest in a Group Strength Training Program - Results of an Exercise Survey
}

\author{
Kevin Rhie, MD*, Danielle M Feger, MS, Rayford R June, MD, Christopher $N$ \\ Sciamanna, MD, MPH and Sharon E Banks, DO, MS
}

Department of Internal Medicine, Penn State Health, USA

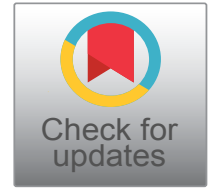

*Corresponding author: Kevin Rhie, MD, Department of Internal Medicine, Penn State Health, 500 University Drive, Hershey, PA 17033, USA, Tel: 717-531-8903, Fax: 717-531-2034

\begin{abstract}
Background: Exercise has proven benefits in rheumatologic disease including reducing inflammation and improving symptoms. A Group Strength Training (GST) program design has improved adherence to exercise in primary care patients but the effect is unknown in rheumatology patients. We examined the interest of rheumatology patients with different diagnoses and the effect of comorbidities in pursuing an organized GST program.

Methods: We conducted a cross-sectional survey of patients from a rheumatology practice in central Pennsylvania in February and April 2017. This survey assessed selfreported interest of patients in a GST program in addition to demographics, comorbidities, and quality of life measures. Primary care data from a previous survey were used for comparative analysis for the primary outcome: interest in a GST program.

Results: Fifty percent of rheumatology patients were interested in a GST program and there was no difference of interest compared to primary care patients $\left(X^{2}=2.04, p=\right.$ $0.15)$. There was no difference in interest in a GST program for rheumatology patients with poor health compared to patients with good health $(\mathrm{OR}=0.9, p=0.8)$. Female patients were more interested in a group strength training program than male patients $(\mathrm{OR}=3.7, p=0.001)$. Patients with a BMI of $25-30(\mathrm{OR}=2.2, p=0.04)$ or $>30(\mathrm{OR}=1.7$, $p=0.12$ ) were more interested compared to those with a normal BMI. There was no difference in interest in group strength training regardless of rheumatology diagnosis or comorbidities.

Conclusion: Our data suggest that rheumatology patients are interested in a GST program regardless of disease, medical comorbidities, perceived mental or physical health, or education level. Further study is needed to determine the effects of GST on rheumatologic diseases.
\end{abstract}

\begin{abstract}
Keywords
Group, Strength, Rheumatology, Exercise, Interest

\section{List of Abbreviations}

RA: Rheumatoid Arthritis; SLE: Systemic Lupus Erythematosus; PsA: Psoriatic Arthritis; AS: Ankylosing Spondylitis; SS: Sjogren's Syndrome; GST: Group Strength Training; OA: Osteoarthritis; FMS: Fibromyalgia; BMI: Body Mass Index; GIM: General Internal Medicine
\end{abstract}

\section{Introduction}

Patients treated in rheumatology practices suffer from a wide variety of debilitating diseases including but not limited to Rheumatoid Arthritis (RA), Systemic Lupus Erythematosus (SLE), Psoriatic Arthritis (PsA), Ankylosing Spondylitis (AS), and Sjogren's Syndrome (SS). Medical treatment of these diseases typically targets the inflammatory pathway with the progressive use of immunosuppressant medications $[1,2]$. These medications, while effective, are also associated with complications such as opportunistic infections and medication related side effects $[1,3]$. Adherence and availability of medications are limited secondary to high costs especially of biologic medications [3,4].

The benefit of exercise as a treatment modality is not a novel concept. It is known that exercise can decrease inflammation in both healthy patients and patients with rheumatic disease [5]. It can also decrease disease activity, fatigue, pain; improve strength, function, and have a positive effect on rheumatology patients' overall health and quality of

Citation: Rhie K, Feger DM, June RR, Sciamanna CN, Banks SE (2019) Determining Rheumatology Patient Interest in a Group Strength Training Program - Results of an Exercise Survey. Int J Sports Exerc Med 5:121. doi.org/10.23937/2469-5718/1510121

Accepted: February 18, 2019; Published: February 20, 2019

Copyright: (C) 2019 Rhie K, et al. This is an open-access article distributed under the terms of the Creative Commons Attribution License, which permits unrestricted use, distribution, and reproduction in any medium, provided the original author and source are credited. 
life [5-10]. Resistance training in particular has been shown in rheumatology patients to be associated with improvement in aerobic capacity and muscle strength $[6,11]$. In addition, rheumatology patients can have an increased incidence of cardiovascular disease and poor physical fitness is a predictor of increased mortality in rheumatology patients $[12,13]$. However, patient engagement in physical activity through exercise programs remains a problem in rheumatology clinics. Rheumatology patients often do not exercise regularly [14] and patients often avoid physical activity secondary to misinformation and fear [15]. The feasibility or benefit of a strength training program in rheumatology patients has not been previously well described, and strength training specifically is generally not suggested as a specific treatment recommendation perhaps due to lack of evidence. A rheumatology patient specific community Group Strength Training (GST) program may provide a social atmosphere to improve adherence to exercise which can then provide an adjunctive therapy for rheumatology patients in addition to medications to help control disease activity. It is unknown if a GST program involving only rheumatology patients would improve adherence or potentially offer a nonpharmacologic treatment intervention for patients with rheumatic disease. We conducted a survey to evaluate patient interest in a GST program. Our primary objective was to investigate rheumatology patient interest in a rheumatology patient specific GST program intervention. We hypothesized that rheumatology patients regardless of disease would be interested in GST programs.

\section{Methods}

A validated health and behaviors survey used in primary care was modified for a rheumatology specific population within the same health system [16] (Appendix 1). The questionnaire included questions to assess patient interest in a GST program, demographic information, and self-reported quality of life measures. The anonymous survey was approved as a quality improvement project without formal review by the Penn State College of Medicine institutional review board. All patients at two rheumatology clinics in central Pennsylvania were provided surveys during the months of February and April 2017.

Interest in a GST program was assessed using the question, "Would you consider participating in any of the following: A group program to increase your muscle strength" with "Yes" or "No" responses. Mental and physical quality of life were assessed using the following questions from the Healthy Days Measure from the Centers for Disease Control and Prevention, "Thinking about your physical health, which includes physical illness and injury, for how many days during the past 30 days was your physical health NOT good? Now thinking about your mental health, which includes stress, depression, and problems with emotions, for how many days during the past 30 days was your mental health NOT good?" [17] Self-reported health was assessed using the question which has been shown to predict future hospitalization and death, "In general, how is your health", with available responses including: "Excellent", "Very Good", "Good", "Fair", and "Poor" [18]. Physical activity was assessed using the questions developed by Greenwood, et al. and the National Institute of Health Interview Survey, "How many days during the past week did you perform physical activities where your heart beats faster and your breathing is harder than normal for 30 minutes or more? How many days during the past week did you perform physical activities specifically designed to strengthen your muscles such as lifting weights or doing calisthenics", to measure both aerobic and anaerobic activity respectively $[19,20]$. Choices for diagnoses included rheumatoid arthritis, systemic lupus erythematosus, psoriatic arthritis, osteoarthritis, fibromyalgia, ankylosing spondylitis, Sjogren's syndrome and "other". Respondents were able to indicate multiple diagnoses. Co-morbidity choices were limited to hypertension, diabetes, hyperlipidemia, and coronary artery disease; subjects were asked to report "Yes" or "No" for each comorbid diagnosis. All demographics and disease characteristics were self-reported.

Chi-square tests of homogeneity were used to test for differences between categorical variables. A multivariable logistic regression model was used to quantify interest in a GST, including all variables of interest regardless of statistical significance at the univariate level. All statistical tests were two-sided with a significance level of 0.05 , and all analyses were performed in SAS 9.4 (Cary, NC). Responses were excluded from analyses if surveys were not returned or if they were returned but did not include enough responses for the statistical model.

\section{Results}

A total of 397 of 656 patients returned surveys with a response rate of $61.6 \%$. Patients had a mean age of 52 and $80 \%$ were female (Table 1). The most common rheumatic diagnoses were RA (39.0\%), fibromyalgia (FMS) (21.4\%), and Osteoarthritis (OA) (19.7\%). Twenty-nine percent of subjects had a Body Mass Index (BMI) $\leq 25$, $28 \%$ had a BMI of $25-30$, and $44 \%$ had a BMI > 30. Over one third of patients reported high cholesterol (33.5\%) or hypertension (40.3\%) as medical co-morbidities.

The average reported number of days of aerobic exercise over the previous week was 2.2. The average reported number of days of strength training was 1.4 with the majority of patients (58.8\%) reporting 0 days. A majority of patients $(72.7 \%)$ reported at least one day of aerobic or strength exercise over the previous week.

Only $3 \%$ of patients rated their overall health as excellent, while $19 \%$ rated their health as very good, $35 \%$ as fair, and $11 \%$ as poor. Most (62.2\%) patients reported at least 10 days of poor physical health per 
Table 1: Demographics.

\begin{tabular}{|c|c|c|c|c|}
\hline Item & $\begin{array}{l}\text { Overall } \\
N=(\%)\end{array}$ & $\begin{array}{l}\text { Rheumatoid Arthritis } \\
\mathrm{N}=(\%)\end{array}$ & $\begin{array}{l}\text { Osteoarthritis } \\
\mathrm{N}=(\%)\end{array}$ & $\begin{array}{l}\text { Fibromyalgia } \\
\mathrm{N}=(\%)\end{array}$ \\
\hline Age (Years) & $52.0(S D=15.4)$ & $53.2(\mathrm{SD}=15.0)$ & $60.0(S D=11.5)$ & $48.0(S D=13.5)$ \\
\hline $18-44$ & $121(32.4 \%)$ & 39 (26.9\%) & $6(8.0 \%)$ & $31(38.3 \%)$ \\
\hline $45-54$ & $81(21.7 \%)$ & $36(24.8 \%)$ & $18(24.0 \%)$ & $25(30.9 \%)$ \\
\hline $55-64$ & $91(24.3 \%)$ & $28(26.2 \%)$ & $22(29.3 \%)$ & $18(22.2 \%)$ \\
\hline$\geq 65$ & $81(21.7 \%)$ & $32(22.1 \%)$ & $29(38.7 \%)$ & $7(8.6 \%)$ \\
\hline Female & $300(80.0 \%)$ & $113(77.9 \%)$ & 64 (85.3\%) & 73 (90.1\%) \\
\hline Caucasian & $323(81.2 \%)$ & $121(78.1 \%)$ & $66(84.6 \%)$ & $72(84.7 \%)$ \\
\hline Hispanic & $34(9.2 \%)$ & $14(9.7 \%)$ & $6(8.1 \%)$ & $8(10.1 \%)$ \\
\hline Current Smoker & $66(17.2 \%)$ & $25(17.0 \%)$ & $11(14.3 \%)$ & $21(26.3 \%)$ \\
\hline \multicolumn{5}{|l|}{ Level of Education } \\
\hline$<$ High School & $24(6.5 \%)$ & $14(9.8 \%)$ & $6(8.0 \%)$ & $4(4.9 \%)$ \\
\hline High School & $115(31.2 \%)$ & $42(29.4 \%)$ & $22(29.3 \%)$ & $23(28.1 \%)$ \\
\hline Some College & $116(31.4 \%)$ & 47 (32.9\%) & $30(40.0 \%)$ & 40 (48.8\%) \\
\hline College or Higher & $115(31.1 \%)$ & $40(28.0 \%)$ & $17(22.7 \%)$ & $15(18.3 \%)$ \\
\hline BMI $\left(\mathrm{kg} / \mathrm{m}^{2}\right)$ & $30.2(\mathrm{SD}=7.9)$ & $29.9(\mathrm{SD}=7.9)$ & $32.0(\mathrm{SD}=9.1)$ & $31.2(S D=7.8)$ \\
\hline$\leq 25$ & $100(28.6 \%)$ & $39(29.1 \%)$ & $12(17.9 \%)$ & $16(21.9 \%)$ \\
\hline $25-30$ & $97(27.7 \%)$ & $41(30.6 \%)$ & $22(32.8 \%)$ & $19(26.0 \%)$ \\
\hline$>30$ & $153(43.7 \%)$ & $54(40.3 \%)$ & $33(49.3 \%)$ & 38 (52.1\%) \\
\hline \multicolumn{5}{|l|}{ Comorbidities } \\
\hline Diabetes & $52(14.2 \%)$ & $20(14.5 \%)$ & $13(17.8 \%)$ & $10(13.0 \%)$ \\
\hline High Cholesterol & $123(33.5 \%)$ & $46(32.9 \%)$ & $34(47.2 \%)$ & $22(28.2 \%)$ \\
\hline Hypertension & $151(40.3 \%)$ & $53(37.1 \%)$ & $38(52.1 \%)$ & $31(38.8 \%)$ \\
\hline Coronary Artery Disease & $34(9.2 \%)$ & $14(9.7 \%)$ & $8(11.0 \%)$ & $5(6.5 \%)$ \\
\hline Fibromyalgia & $85(21.4 \%)$ & $26(16.8 \%)$ & $31(41.0 \%)$ & $85(100.0 \%)$ \\
\hline Days of Aerobic Exercise/Week & $2.2(\mathrm{SD}=2.3)$ & $2.0(\mathrm{SD}=2.2)$ & $2.0(S D=2.1)$ & $2.3(\mathrm{SD}=2.3)$ \\
\hline 0 & $132(36.8 \%)$ & $57(40.7 \%)$ & $24(35.3 \%)$ & 26 (34.7\%) \\
\hline $1-3$ & $133(37.1 \%)$ & $50(35.7 \%)$ & $30(44.1 \%)$ & $28(37.3 \%)$ \\
\hline $4-7$ & $94(26.2 \%)$ & $33(23.6 \%)$ & $14(20.6 \%)$ & $21(28.0 \%)$ \\
\hline Days of Strength Exercise/Week & $1.4(2.0)$ & $1.5(2.1)$ & $1.1(1.7)$ & $1.0(1.7)$ \\
\hline 0 & $211(58.8 \%)$ & 78 (56.9\%) & $44(61.1 \%)$ & $51(64.6 \%)$ \\
\hline $1-3$ & $94(26.2 \%)$ & $37(27.0 \%)$ & $20(27.8 \%)$ & $19(24.1 \%)$ \\
\hline $4-7$ & $54(15.0 \%)$ & $22(16.1 \%)$ & $8(11.1 \%)$ & $9(11.4 \%)$ \\
\hline \multicolumn{5}{|l|}{ Physical Activity } \\
\hline None & $99(27.3 \%)$ & $44(31.4 \%)$ & $18(25.0 \%)$ & $23(29.5 \%)$ \\
\hline 1+ Days/Week & $264(72.7 \%)$ & $96(68.6 \%)$ & $54(75.0 \%)$ & $55(70.5 \%)$ \\
\hline \multicolumn{5}{|l|}{ General Health Rating } \\
\hline Excellent & $11(2.8 \%)$ & $2(1.3 \%)$ & $1(1.3 \%)$ & $0(0.0 \%)$ \\
\hline Very Good & $75(19.2 \%)$ & $23(15.1 \%)$ & $8(10.3 \%)$ & $6(7.2 \%)$ \\
\hline Good & $128(32.8 \%)$ & $51(33.6 \%)$ & $32(41.0 \%)$ & $23(27.7 \%)$ \\
\hline Fair & $135(34.6 \%)$ & $57(37.5 \%)$ & $26(33.3 \%)$ & $36(43.4 \%)$ \\
\hline Poor & $41(10.5 \%)$ & $19(12.5 \%)$ & $11(14.1 \%)$ & $18(21.7 \%)$ \\
\hline $\begin{array}{l}\text { Days of Poor Physical Health/ } \\
\text { Month }\end{array}$ & $13.6(S D=10.6)$ & $14.2(\mathrm{SD}=10.4)$ & $13.7(\mathrm{SD}=10.7)$ & $18.0(S D=9.6)$ \\
\hline 0 & $49(13.9 \%)$ & $17(12.6 \%)$ & $8(12.5 \%)$ & $4(5.3 \%)$ \\
\hline $1-9$ & $84(23.9 \%)$ & $28(20.7 \%)$ & $17(26.6 \%)$ & $11(14.7 \%)$ \\
\hline$\geq 10$ & $219(62.2 \%)$ & $90(66.7 \%)$ & 39 (60.9\%) & $60(80.0 \%)$ \\
\hline Days of Poor Mental Health/Month & $9.8(S D=10.7)$ & $9.2(S D=10.6)$ & $9.7(S D=10.6)$ & $13.6(S D=11.3)$ \\
\hline 0 & 117 (33.0\%) & $54(39.7 \%)$ & $24(35.8 \%)$ & $12(15.6 \%)$ \\
\hline $1-9$ & $80(22.5 \%)$ & $24(17.7 \%)$ & $13(19.4 \%)$ & $20(26.0 \%)$ \\
\hline$\geq 10$ & 158 (44.5\%) & $58(42.7 \%)$ & 30 (44.8\%) & 45 (58.4\%) \\
\hline
\end{tabular}

month and $44.5 \%$ of patients reported at least 10 days of poor mental health per month.

Approximately half ( $50.1 \%$ ) of rheumatology patients were interested in a GST program. Female rheumatology patients were more interested in GST than male patients (Odds Ratio $[\mathrm{OR}]=3.7, p=0.001$ ). A lower percentage of men $(31 \%)$ versus women $(55 \%)$ were interested in
GST. Patients with a BMI of $25-30(\mathrm{OR}=2.2, p=0.04)$ or $>30(O R=1.7, p=0.12)$ were also more interested compared to those with a normal BMI. Between those interested in GST and those not, there was no difference in average age (51.6 years vs. 51.1 years, $p=$ $0.95)$, proportion of Caucasians ( $85 \%$ vs. $87 \%, p=0.55$ ), proportion of Hispanics ( $8 \%$ vs. $9 \%, p=0.63$ ), presence 
Table 2: Comparison between persons interested in Group Strength Training and not interested.

\begin{tabular}{|c|c|c|c|}
\hline Item & Interest $\mathbf{N}=(\%)$ & No Interest $\mathbf{N}=(\%)$ & P-value \\
\hline Age (Years) & $51.6(\mathrm{SD}=14.8)$ & $51.5(\mathrm{SD}=16.3)$ & 0.95 \\
\hline $18-44$ & $57(48.7 \%)$ & $60(51.3 \%)$ & \\
\hline $45-54$ & $36(46.2 \%)$ & $42(53.9 \%)$ & \\
\hline $55-64$ & $47(57.3 \%)$ & $35(42.7 \%)$ & \\
\hline$\geq 65$ & $35(48.0 \%)$ & $38(52.1 \%)$ & \\
\hline Female & $155(88.1 \%)$ & $127(73.0 \%)$ & $0.0004^{\dagger}$ \\
\hline Caucasian & $150(85.2 \%)$ & $153(87.4 \%)$ & 0.55 \\
\hline Hispanic & $14(8.0 \%)$ & $16(9.4 \%)$ & 0.63 \\
\hline Current Smoker & $26(44.1 \%)$ & $33(55.9 \%)$ & 0.28 \\
\hline Level of Education & & & 0.11 \\
\hline$<$ High School & $6(28.6 \%)$ & $15(71.4 \%)$ & \\
\hline High School & $49(45.8 \%)$ & $58(54.2 \%)$ & \\
\hline Some College & $61(55.5 \%)$ & $49(44.6 \%)$ & \\
\hline College or Higher & $56(51.9 \%)$ & $52(41.2 \%)$ & \\
\hline BMI $\left(\mathrm{kg} / \mathrm{m}^{2}\right)$ & $31.1(\mathrm{SD}=7.9)$ & $29.7(\mathrm{SD}=8.1)$ & 0.10 \\
\hline$\leq 25$ & $39(42.9 \%)$ & $52(57.1 \%)$ & \\
\hline $25-30$ & $46(51.7 \%)$ & $43(48.3 \%)$ & \\
\hline$>30$ & $84(56.0 \%)$ & $66(44.0 \%)$ & \\
\hline \multicolumn{4}{|l|}{ Comorbidities } \\
\hline Diabetes & $25(56.8 \%)$ & $19(43.2 \%)$ & 0.44 \\
\hline High Cholesterol & $66(56.4 \%)$ & $51(43.6 \%)$ & 0.17 \\
\hline Hypertension & $72(53.7 \%)$ & $62(46.3 \%)$ & 0.42 \\
\hline Coronary Artery Disease & $13(40.6 \%)$ & $19(59.4 \%)$ & 0.22 \\
\hline Fibromyalgia & $38(48.7 \%)$ & $40(51.3 \%)$ & 0.78 \\
\hline Days of Aerobic Exercise/Week & $2.3(\mathrm{SD}=2.2)$ & $2.0(\mathrm{SD}=2.3)$ & 0.63 \\
\hline $0(\%)$ & $55(46.6 \%)$ & $63(53.4 \%)$ & \\
\hline $1-3(\%)$ & $66(51.6 \%)$ & $62(48.4 \%)$ & \\
\hline 4-7 (\%) & $47(54.7 \%)$ & $39(45.4 \%)$ & \\
\hline Days of Strength Exercise/Week & $1.4(\mathrm{SD}=2.0)$ & $1.4(\mathrm{SD}=2.1)$ & 1.00 \\
\hline $0(\%)$ & $94(48.7 \%)$ & $99(51.3 \%)$ & \\
\hline $1-3(\%)$ & $51(56.0 \%)$ & $40(44.0 \%)$ & \\
\hline $4-7(\%)$ & $22(44.9 \%)$ & $27(55.1 \%)$ & \\
\hline Physical Activity & & & 0.28 \\
\hline None & $42(46.2 \%)$ & $49(53.9 \%)$ & \\
\hline 1+ Days/Week & $130(52.9 \%)$ & $116(47.2 \%)$ & \\
\hline General Health Rating & & & 0.16 \\
\hline Excellent $(\%)$ & $2(20.0 \%)$ & $8(80.0 \%)$ & \\
\hline Very Good (\%) & $30(45.5 \%)$ & $36(55.6 \%)$ & \\
\hline Good (\%) & $63(53.9 \%)$ & $54(46.2 \%)$ & \\
\hline Fair (\%) & $64(53.8 \%)$ & $55(46.2 \%)$ & \\
\hline Poor $(\%)$ & $13(40.6 \%)$ & $19(59.4 \%)$ & \\
\hline Days of Poor Physical Health/Month & $13.7(\mathrm{SD}=10.0)$ & $13.0(\mathrm{SD}=10.8)$ & 0.96 \\
\hline $0(\%)$ & $18(40.9 \%)$ & $26(59.1 \%)$ & \\
\hline $1-9(\%)$ & $39(49.4 \%)$ & $40(50.6 \%)$ & \\
\hline$\geq 10(\%)$ & $108(54.6 \%)$ & $90(45.5 \%)$ & \\
\hline Days of Poor Mental Health/Month & $9.8(10.6)$ & $9.4(10.7)$ & 0.99 \\
\hline $0(\%)$ & $51(47.7 \%)$ & $56(52.3 \%)$ & \\
\hline $1-9(\%)$ & $43(55.8 \%)$ & $34(44.2 \%)$ & \\
\hline$\geq 10(\%)$ & $74(52.1 \%)$ & $68(47.9 \%)$ & \\
\hline
\end{tabular}
$+P<0.05$.

of comorbidities, aerobic exercise days over the previous week ( 2.3 vs. 2.0 days, $p=0.63$ ), strength exercise days over the previous week (1.4 days vs. 1.4 days, $p=1.00$ ), days of poor physical health per month (13.7 days vs. 13.0 days, $p=0.96)$, and days of poor mental health per month (9.8 days vs. 9.4 days, $p=0.99$ ). There was no difference in interest in a GST for rheumatology patients with "Fair" or "Poor" health compared to patients with
"Excellent", "Very Good", or "Good" health (OR $=0.9$, $p=0.8$, Table 2). Notably, there was also no difference in GST interest between rheumatic diagnoses (Table 3).

\section{Discussion}

It is known that rheumatology patients exercise less than their healthy counterparts and previous studies have estimated that $80 \%$ of rheumatology patients are 
Table 3: Comparison between persons interested in Group Strength Training and not interested by diagnosis.

\begin{tabular}{|l|l|l|l|}
\hline Item & $\begin{array}{l}\text { Interested } \\
\mathbf{N}=\mathbf{( \% )}\end{array}$ & $\begin{array}{l}\text { Not Interested } \\
\mathbf{N}=\mathbf{( \% )}\end{array}$ & P-value \\
\hline Rheumatoid Arthritis & $64(48.9 \%)$ & $67(51.2 \%)$ & 0.71 \\
\hline Lupus & $28(58.3 \%)$ & $20(41.7 \%)$ & 0.22 \\
\hline Psoriatic Arthritis & $16(48.5 \%)$ & $17(51.5 \%)$ & 0.84 \\
\hline Osteoarthritis & $34(50.0 \%)$ & $34(50.0 \%)$ & 0.98 \\
\hline Fibromyalgia & $38(48.7 \%)$ & $40(51.3 \%)$ & 0.78 \\
\hline Ankylosing Spondylitis & $8(57.1 \%)$ & $6(42.3 \%)$ & 0.59 \\
\hline Sjogren's Syndrome & $17(54.8 \%)$ & $14(45.2 \%)$ & 0.58 \\
\hline
\end{tabular}

physically inactive $[12,14]$. Barriers to physical activity include physical limitations such as pain, fatigue, and physical capability as well as psychological aspects such as lack of enjoyment, motivation, confidence, and fear $[15,21]$. In our survey, when compared to a similar survey by Sciamanna, et al. [15] of general internal medicine patients, there was no difference with an unadjusted chi-square test in the number of rheumatology patients interested in GST ( $55 \%, p=0.15)$. Interestingly, perceived "Fair" or "Poor" health was higher in rheumatology patients (45.1\%) compared to GIM patients $(18.8 \%$, $p<0.0001)$ implying that rheumatology patients have worse perceived general health than published GIM patients [16]. This is consistent with previous studies that have shown a substantial impact of rheumatologic disease on physical and mental health [22]. But despite these physical barriers to engaging in physical activity, a majority of rheumatology patients $(50.1 \%)$ are nonetheless still interested in GST. We believe this to be because of several reasons. First, a rheumatology specific program may be more beneficial than a typical exercise program designed for healthy patients and this may lead to improved adherence. A previous study has shown that a tailor-made exercise program for patients with knee OA had an adherence rate of greater than $90 \%$ [23]. Rheumatology patients may typically avoid traditional exercise programs which do not consider the disease specific physical limitations of these patients [21]. In addition, exercising in a group can provide a social environment and encourage patients to be more engaged in physical activity. This social aspect is likely what makes group activities such as spin classes, yoga classes, dance fitness, and SilverSneakers ${ }^{\circledR}$ popular. In fact, exercising in group settings has been shown to have more health benefits compared to exercising alone [24]. It is not surprising that certain group fitness classes are popular among females and in our findings, females were more likely to be interested GST. In addition, people with physical limitations related to their rheumatologic disease would be supportive of others in a group who would have similar limitations.

Common cardiovascular risk factors such as diabetes, hypertension, hyperlipidemia, and coronary artery disease were unsurprisingly also common in our surveyed rheumatology patients which are consistent with findings from a previous study [25]. It is well known that exercise can help treat these conditions [26]. Overweight patients (BMI 25-30) may be interested to adopt healthy lifestyle choices for additional reasons outside of their rheumatologic disease and have the most to gain from exercise.

This survey does have limitations. Data were only collected in central Pennsylvania and results may not be generalizable to other geographic settings. There is a possibility of response bias as respondents self-reported their diagnosis. In addition, within a rheumatology practice, there is a wide range of rheumatology diagnoses and varying degrees of disease activity which can affect the interest level of patients. Objectively measuring disease activity was not possible with this survey to assess if higher or lower disease activity is associated with being interested in a GST program. However, we do know that overall health was fair/poor in our surveyed patients which is similar to other studies which showed rheumatology patients have overall poor health related quality of life [22]. The rates of fair/poor health are quite high in this clinic compared to primary care practices. In theory, a GST program would only be offered to patients with stable disease and physically able to participate since these are the patients who would be more likely to adhere to an exercise program. A respondent's prior experience with GST or any other exercise program may have impacted his or her current interest in a GST program depending on whether this prior experience was positive or negative. This survey did not assess for respondents' prior experience with GST and this is an area for future investigation to further determine barriers to participating in GST and improve adherence.

Even though the majority of questionnaire respondents showed an interest in a GST program, we recognize that it is only a slim majority and there are still many patients who are not interested. Finding methods to engage these patients who are not interested and increasing interest in GST program is a foreseeable challenge. Even for the patients who are interested, we hope that interest will translate into future participation but there are still obstacles to overcome. Logistical challenges such as a convenient location and time will certainly affect an individual's ability to participate in a GST program.

Despite these limitations, our findings suggest 
that rheumatology patients may be interested in GST regardless of disease, age, medical comorbidities, perceived mental or physical health or education level. A particular emphasis in program development may be placed on female and overweight patients as they showed an increased interest in GST programs. Future studies should examine if a GST program design improves exercise adherence in rheumatology patients.

\section{Conclusions}

This study shows that rheumatology patients are interested in GST across a wide range of diagnoses, comorbidities, and perceived general health. It appears that women in rheumatology clinics are more interested in a GST program. Interest in a GST program does not necessarily lead to better adherence and future studies should investigate the barriers to participation and methods to increase adherence. Designing an exercise programing specifically for rheumatology patients needs special care. Future studies are needed to determine the effects of GST on disease activity in rheumatic disease and the overall health of rheumatology patients.

\section{Declarations}

\section{Ethics approval and consent to participate}

This study was approved by the Institutional Review Board at Penn State Health under exempt status December of 2016.

\section{Consent for publication}

Not Applicable.

\section{Availability of data and material}

The datasets used and/or analyzed during the current study are available from the corresponding author on reasonable request, and pertinent data generated or analyzed used for the discussion and conclusions of this study are included in this published article.

\section{Competing interests}

"The authors declare that they have no competing interests".

\section{Funding}

Dr. June was supported, in part, by the National Center for Advancing Translational Sciences, Grant UL1 TR002014 and KL2 TR002015 of the Penn State Clinical and Translational Research Institute. The content is solely the responsibility of the authors and does not necessarily represent the official views of the NIH.

\section{Authors contributions}

$\mathrm{KR}$ - contributed to the design of the study and writing of the manuscript. DF - analyzed and interpreted the statistics and contributed to the methods section of the manuscript. RJ - contributed to the study design, concept and writing of the manuscript as well as data collection. CS - contributed to the design of the study including background and editorial comments. SB formatted study design, carried out data collection, and helped write and edit the manuscript.

\section{Acknowledgements}

None.

\section{Assistance}

There was no assistance of medical writing experts in the creation of this manuscript.

\section{References}

1. Smolen JS, Aletaha D, McInnes IB (2016) Rheumatoid arthritis. Lancet 388: 2023-2038.

2. Pincus $T$ (1995) Long-term outcomes in rheumatoid arthritis. $\mathrm{Br} J$ Rheumatol 34: 59-73.

3. June RR, Olsen NJ (2016) Room for more IL-6 blockade? Sarilumab for the treatment of rheumatoid arthritis. Expert Opin Biol Ther 16: 1303-1309.

4. De Vera MA, Mailman J, Galo JS (2014) Economics of nonadherence to biologic therapies in rheumatoid arthritis. Curr Rheumatol Rep 16: 460.

5. Kasapis C, Thompson PD (2005) The effects of physical activity on serum C-reactive protein and inflammatory markers: a systematic review. J Am Coll Cardiol 45: 15631569.

6. Verhoeven F, Tordi N, Prati C, Demougeot C, Mougin F, et al. (2016) Physical activity in patients with rheumatoid arthritis. Joint Bone Spine 83: 265-270.

7. Bogdanovic G, Stojanovich L, Djokovic A, Stanisavljevic N (2015) Physical Activity Program Is Helpful for Improving Quality of Life in Patients with Systemic Lupus Erythematosus. Tohoku J Exp Med 237: 193-199.

8. Kelley GA, Kelley KS, Callahan LF (2018) Aerobic Exercise and Fatigue in Rheumatoid Arthritis Participants: A MetaAnalysis Using the Minimal Important Difference Approach. Arthritis Care Res (Hoboken) 70: 1735-1739.

9. Martins NA, Furtado GE, Campos MJ, Leitão JC, Filaire E, et al. (2014) Exercise and ankylosing spondylitis with New York modified criteria: a systematic review of controlled trials with meta-analysis. Acta Reumatol Port 39: 298-308.

10. Larsson A, Palstam A, Löfgren M, Ernberg M, Bjersing $\mathrm{J}$, et al. (2015) Resistance exercise improves muscle strength, health status and pain intensity in fibromyalgia--a randomized controlled trial. Arthritis Res Ther 17: 161.

11. Hurkmans E, van der Giesen FJ, Vliet Vlieland TP, Schoones J, Van den Ende EC (2009) Dynamic exercise programs (aerobic capacity and/or muscle strength training) in patients with rheumatoid arthritis. Cochrane Database Syst Rev.

12. Sokka T, Häkkinen A (2008) Poor physical fitness and performance as predictors of mortality in normal populations and patients with rheumatic and other diseases. Clin Exp Rheumatol 26: S14-S20.

13. del Rincón ID, Williams K, Stern MP, Freeman GL, Escalante A (2001) High incidence of cardiovascular events in a rheumatoid arthritis cohort not explained by traditional cardiac risk factors. Arthritis Rheum 44: 2737-2745.

14. Margiotta DPE, Basta F, Dolcini G, Batani V, Lo Vullo M, et al. (2018) Physical activity and sedentary behavior in 
patients with Systemic Lupus Erythematosus. PLoS One 13: e0193728.

15. Lööf H, Demmelmaier I, Henriksson EW, Lindblad S, Nordgren B, et al. (2015) Fear-avoidance beliefs about physical activity in adults with rheumatoid arthritis. Scand J Rheumatol 44: 93-99.

16. Sciamanna CN, Patel VA, Kraschnewski JL, Rovniak LS, Messina DA, et al. (2014) A Strength Training Program for Primary Care Patients, Central Pennsylvania, 2012. Prev Chronic Dis 11: 107

17. Moriarty DG, Zack MM, Kobau R (2003) The Centers for Disease Control and Prevention's Healthy Days Measures population tracking of perceived physical and mental health over time. Health Qual Life Outcomes 1: 37.

18. DeSalvo KB, Jones TM, Peabody J, McDonald J, Finn S, et al. (2009) Health care expenditure prediction with a single item, self-rated health measure. Med Care 47: 440-447.

19. Greenwood JL, Joy EA, Stanford JB (2010) The Physical Activity Vital Sign: a primary care tool to guide counseling for obesity. J Phys Act Health 7: 571-576.

20. Carlson SA, Fulton JE, Schoenborn CA, Loustalot F (2010) Trend and prevalence estimates based on the 2008 Physical Activity Guidelines for Americans. Am J Prev Med 39: 305-313.
21. Hutton I, Gamble G, McLean G, Butcher H, Gow P, et al. (2010) What is associated with being active in arthritis? Analysis from the Obstacles to Action study. Intern Med J 40: $512-520$.

22. Matcham F, Scott IC, Rayner L, Hotopf M, Kingsley GH, et al. (2014) The impact of rheumatoid arthritis on qualityof-life assessed using the SF-36: a systematic review and meta-analysis. Semin Arthritis Rheum 44: 123-130.

23. Lee FI, Lee TD, So WK (2016) Effects of a tailor-made exercise program on exercise adherence and health outcomes in patients with knee osteoarthritis: a mixedmethods pilot study. Clin Interv Aging 11: 1391-1402.

24. Kanamori S, Takamiya T, Inoue S, Kai Y, Kawachi I, et al. (2016) Exercising alone versus with others and associations with subjective health status in older Japanese: The JAGES Cohort Study. Sci Rep 6: 39151.

25. Dougados $M$, Soubrier $M$, Antunez A, Balint $P$, Balsa $A$, et al. (2014) Prevalence of comorbidities in rheumatoid arthritis and evaluation of their monitoring: results of an international, cross-sectional study (COMORA). Ann Rheum Dis 73: 62-68.

26. Wewege MA, Thom JM, Rye KA, Parmenter BJ (2018) Aerobic, resistance or combined training: A systematic review and meta-analysis of exercise to reduce cardiovascular risk in adults with metabolic syndrome. Atherosclerosis 274: 162-171. 